
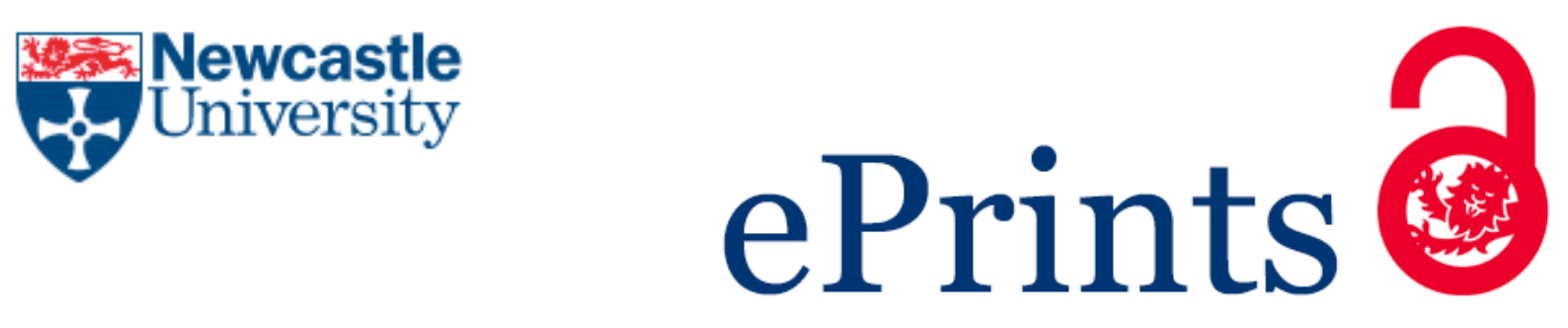

\author{
Balfe M, O'Brien K, Timmons A, O'Sullivan E, \\ Butow P, Gooberman-Hill R, Sharp L. \\ Informal caregiving in head and neck cancer: caregiving activities and \\ psychological well-being. \\ European Journal of Cancer Care (2016) \\ DOI: $10.1111 /$ ecc.12520
}

\title{
Copyright:
}

This is the peer reviewed version of the following article, which has been published in final form at http://dx.doi.org/10.1111/ecc.12520. This article may be used for non-commercial purposes in accordance with Wiley Terms and Conditions for Self-Archiving.

Date deposited:

$29 / 06 / 2016$

Embargo release date:

07 June 2017 


\section{Informal caregiving in head and neck cancer: caregiving activities and psychological}

\section{wellbeing.}

Myles Balfe (Corresponding author), National Cancer Registry of Ireland, Cork Airport Business Park, Cork, Ireland. m.balfe@ucc.ie

2. Katie 0' Brien, National Cancer Registry of Ireland, Cork Airport Business Park, Cork, Ireland. kobrien@ncri.ie

3. Aileen Timmons, National Cancer Registry of Ireland, Cork Airport Business Park, Cork, Ireland. atimmons@ncri.ie

4. Phyllis Butow, Centre for Medical Psychology, University of Sydney, Sydney, Australia. phyllis.butow@sydney.edu.au

5. Eleanor 0' Sullivan, School of Dentistry, University College Cork, Cork, Ireland. Eleanor.osullivan@ucc.ie

6. Rachael Gooberman-Hill, Musculskeletal Research Unit, University of Bristol, Bristol, UK. R.Gooberman-Hill@bristol.ac.uk

7. Linda Sharp, National Cancer Registry of Ireland, Cork Airport Business Park, Cork, Ireland. lsharp@ncri.ie 


\section{Abstract}

The purpose of this study was to quantify the cancer support activities that informal carers of head and neck cancer survivors engage in; and the relationships between care activities and psychological wellbeing. Respondents answered a survey detailing their caring activities, the amount of time that they spent on those activities and how comfortable they felt engaging in them. Psychological wellbeing was assessed by the Depression Anxiety Stress Scales-21. 197 carers took part in the study. The majority (76\%) were women, mean age 57.4. In the past month, $45 \%$ of carers did not spend any time per week helping their relative/friend with general caring activities such as cleaning the house; $31 \%$ spent $1-19$ hours/week and $23 \%$ spent 20 or more hours/week doing so. Most carers were comfortable assisting their relative/friend, though more carers felt uncomfortable assisting with cancer specific support tasks (31\% uncomfortable helping with medication) compared with general support tasks (7\% uncomfortable helping with appointments). Feeling uncomfortable was a significant predictor of experiencing depression and anxiety. Caring for more than 20 hours a week was a borderline predictor for experiencing stress. Efforts to identify and address the reasons why carers are discomforted by caring could mitigate psychological issues in this group.

Keywords: Carer, survivor, head, neck, cancer, burden, depression, anxiety, stress, time. 


\section{Background}

\section{Introduction}

Head and neck cancer is the $6^{\text {th }}$ most common form of cancer worldwide, with over 500,000 new cases diagnosed each year (Mehanna et al. 2010). Most cases occur in individuals over 40 years of age and alcohol and tobacco use are the main etiological factors (Mehanna et al. 2010). Head and neck cancer is associated with high morbidity; it can cause disfigurement and directly or indirectly (as a result of medical treatment) lead to substantial difficulties with eating, swallowing and speaking (Precious et al. 2012). It thereby has the potential to seriously undermine an individual's quality of life (Precious et al. 2012). As a result, people with head and neck cancer often have complex needs (Ross et al. 2010).

While patients with head and neck cancer receive their cancer-directed treatment in hospitals, much of their ongoing care and support actually occurs in the community (Stenberg et al. 2010). There, management of the condition and its complications is often supported by family and friends (collectively referred to as informal carers or caregivers) (Given et al. 2001; Yabroff and Youong, 2009). To date only a limited amount of research has been conducted specifically on the helping activities that cancer carers engage in (McMullen et al. 2014) and the time that caregivers spend on these activities (Yabroff and Youong, 2009). The available research has found that carers provide both cancer-specific and general assistance (Given et al. 2001) such as preparing meals, helping with transport and household tasks, providing emotional support and assisting communication with providers (Given et al. 2001, Girgis and Lambert, 2009; Mosher et al. 2013). One recent study found that many carers appeared to be performing five or more support functions (Precious et al. 2012); and, in another, a substantial number of cancer carers reported feeling overwhelmed by the number of care related tasks that they have to manage (Girgis et al. 2013). For some carers the time commitment involved in 
caregiving is substantial and equivalent to a fulltime job (Girgis et al. 2013). As people with cancer are living longer as a result of improved medical treatment (Maddens et al. 2012) an increasing number of carers are providing support over the longer term (what is referred to as the post-treatment phase, or survivorship phase, of caring).

Given the sometimes substantial time and task demands of caregiving for someone recovering from cancer, it is perhaps unsurprising that some carers report poor psychological wellbeing. For example many caregivers, including carers of people with head and neck cancer, appear to experience emotional distress as a result of caring (Nijboer et al. 1998; Given et al. 2001; Oyebode, 2003; Verdonck-de Leeuwh, 2007; Drabe et al. 2008; Ross et al. 2010; Stenberg et al. 2010; Longacre et al. 2012; Jayani and Hurria, 2012; Romito et al. 2013; Lee et al. 2014). Some studies, in fact, have found that the rates of anxiety and depression experienced by carers exceeds those among patients (Vickery et al. 2003; Lambert et al. 2013).

Identifying psychological distress, and the risk factors and causes of such distress in caregivers is an important end not only in itself, but also because previous research suggests that carers' distress can undermine patients' functioning (Dempster et al. 2011; Longacre et al. 2012; OtisGreen et al. 2012). A number of factors have been identified as being associated with increased risk of psychosocial distress in head and neck cancer carers including: having a strong fear of recurrence (Hodges and Humphris 2009), being female (Blood et al. 1994) being unemployed and having lower educational attainment (Lee et al. 2014), greater time spent caregiving (Ross et al. 2010), a disrupted life schedule and the presence of feeding tubes (Verdonck-de Leeuw et al. 2010). Despite the findings mentioned here, however, overall relatively few studies have aimed to identify risk factors for poor psychological health in head and neck cancer carers' (Lee et al. 2014); and most of those (including the studies identified her) have sought to identify risk factors in the period soon after diagnosis and/or treatment (Badr et al 2010; Hodges and Humphris 2009; Ross et al. 2010; Verdonck-de Leeuw et al. 2010). In particular, very few studies appear to have investigated whether aspects of the caregiving burden (such as time spent on caring or tasks performed) are associated with head and neck carers' psychological wellbeing.

We therefore conducted a study to quantify: the cancer support activities that long-term carers of survivors with head and neck cancer engage in; how comfortable they feel engaging in these 
tasks; the time that carers spend on these tasks; and the relationship between psychological distress and caring in this group.

3

Methods

Design

This investigation was part of a larger study that examined the post-treatment experiences of survivors of head and neck cancer in Ireland (Thomas et al. 2014; Pearce et al. 2014). For that larger study, 583 head and neck cancer survivors completed a survey that examined their unmet needs. Additionally, 17 survivors and 32 healthcare professionals completed pilot qualitative interviews that focused a). on survivors' unmet needs and $b$ ). the tasks that carers assisted survivors with.

We asked all 583 head and neck cancer survivors who had completed the postal questionnaire for permission to contact their caregivers (defined as a family member, friend or another person who had been helping take care of them since their diagnosis, if they had one). Two hundred and eighty five survivors granted us permission. We wrote to all 285 carers providing them with information about the study, and indicated that we would send them a questionnaire two weeks after they received the initial contact letter. Questionnaires were then sent to all 285 carers, 197 of whom responded (69\% response rate). When carers returned their survey they also had to return a signed consent form. Ethical approval for the carer component of the study was provided by nine Irish university hospital ethics committees.

\section{Survey}

\section{Demographics}

Carers were asked to report the following demographic characteristics: sex; relationship status (married/partner vs. not married/no partners); children (yes/no); employment status; private health insurance (yes/no); medical card (yes/no) (entitling them to free medical care in Ireland-this is generally awarded to people with low incomes). Time since 
survivors' diagnosis was obtained the National Cancer Registry of Ireland's patient records database, and was therefore not based on carer self-report.

DASS-21

To assess carers' psychological wellbeing we used the validated 21 question version of the Depression Anxiety and Stress Scale. The DASS measures psychological wellbeing in three dimensions (anxiety, depression, distress) and is considered to be a reliable measure with good construct validity (Henry and Crawford, 2005).

Financial stress and strain

Following the definitions of Francouer (2005) we examined finanical stress (which stems 
1 Twelve specific head and neck related care activities that carers assisted their 2 relative/friends with were identified from interviews with survivors and healthcare 3 professionals. These activities were: preparing special foods; helping with 4 communication; helping to look after feeding tubes; helping to look after breathing tubes;

5 helping with medical complications such as fluid going down the airway; helping with 6 mouth care routines; helping their relative/friend to manage their emotions; helping their 7 relative/friend to deal with changes to their appearance; looking after their 8 relative/friend's appointments; helpiong with financial matters; helping with communication difficulties; and helping their relative/friend to navigate the health system. For each of these activities carers were asked if they helped their relative/friend (yes/no); and if they did help them, if they felt comfortable doing so (answering a five point likert scale ranging from very uncomfortable to very comfortable).

\section{Data analysis}

\section{All analysis was carried out using Stata 12.}

Carers' demographic characteristics and financial status were summarised using simple descriptive statistics and chi-square tests.

Caring activities were measured in three ways: 1) time spent caring per week in the past month, 2) number of head and neck specific care tasks engaged in in the past month and 3) comfort with head and neck cancer specific caring activities. Responses to the twelve questions relating to time spent caring were summed to get total time spent on caring activities per week in the stipulated time period. As there was a high proportion (45\%) of respondents who did not spend any time on these caring activities, the total time spent caring per week in the past month was transformed into a categorical variable with three levels. We were interested in comparing those who did no caring (0 hours), a moderate amount (1-19 hours) and a high amount (20+ hours) of caring in the activities of daily living time use instrument. If a respondent did not fill in any hours for any of the 12 tasks, we assumed that s/he spent no hours caring.

The three DASS-21 psychological sub-scales were analysed separately. Respondents were included in an analysis if all seven questions of a sub-scale were completed. Scores from the seven questions on each scale were totalled using standard methods (Lovibond and Lovibond, 
1995), and each response was categorised according to previously defined cut-off points. On each sub-scale, the categories were: normal, mild, moderate, severe and very severe. This classification was reduced to binary outcomes for analysis. Following Sharp et al. (2013) Respondents were classified based on whether the response was normal or otherwise, e.g. depression of any severity (mild/moderate/severe/very severe) versus none. Similar outcome variables were created for any anxiety, and any stress.

Multiple logistic regression was used to identify whether aspects of caregiving burden (specifically time spent caring and discomfort with one or more head and neck cancer specific tasks) were significantly associated with depression, anxiety and stress, after adjusting for other factors. Time since diagnosis was considered for inclusion in the models as it was hypothesised that those further out from diagnosis may be providing less care and thus have better psychological health. In addition financial variables were also considered for inclusion as they have been shown to be associated with psychological well-being (Sharp et al. 2013). The financial variables were: ability to make ends meet in the past month, private health insurance, effect of caring on ability to make ends meet, how respondent feels about household finances since relative/friend's diagnosis and having a medical card. Furthermore, we adjusted for socio-demographic variables (age, gender, marital status, children, employment status).

In addition to our main variables of interest - time burden and discomfort, a covariate was included in the multivariable models if it had p-value of less than 0.1 in a likelihood ratio test comparing the model containing the variable with a nested model excluding the variable. Model goodness-of-fit was checked using the Hosmer and Lemeshow test.

\section{Missing data}

Compared to those who completed the DASS-21 subscales, respondents who partially completed or did not complete these were older, and a higher proportion had a medical card, children and were not working at time of diagnosis, while a lower proportion had private health insurance.

Almost 6\% (11) of subjects did not report whether they had private health insurance and we did not have a date of diagnosis (for the care recipient ) for $4 \%$ (7) cases. The level of missing 


\section{Results}

5

6 Respondents' characteristics and financial status

7

8 Caregivers' demographic characteristics are shown in Table 1. Three-quarters (76\%) of

data in other variables was lower and subjects with missing data for any of these covariates were excluded from relevant analyses.

respondents were women and the majority (89\%) were in a relationship (married or living with a partner). Respondents' mean age was 57.4 years (standard deviation: 12.3 years). For $46 \%$ of carers the time between their relative's/friend's diagnosis and when they completed the questionnaire was less than five years; for $35 \%$ it was between 5 and 10 years; and for $15 \%$ it was over ten years. Just over half of respondents had a medical card. The majority of respondents $(67 \%)$ were not in paid work.

Half of carers indicated that they found it difficult to make ends meet financially in the past month and just under half (48\%) indicated that caring for their relative/friend with head and neck cancer made their financial situation more difficult. Just over half (58\%) of carers indicated that they felt more concerned about their household financial situation since their relative's/friend's diagnosis.

Information on demographic and clinical characteristics of survivors in contained in table S1.

Time spent per week on general and cancer-specific caring activities

Table 2 describes the results of the activities of daily living time use instrument (Hanly et al. 2013). For each individual task, most carers did not spend any time per week helping their relative/friend. However for most individual tasks a small percentage of carers (between 5\% and $15 \%$ ) spent 6 or more hours a week helping their relative/friend. Individual tasks on which a relatively large proportion of carers were spending at least one hour a week on included: liaising with healthcare services (38\%), preparing food (33\%) and cleaning the house (32\%). Additionally, some carers were spending substantial amounts of time per week helping their relative/friend, with $23 \%$ spending 20 or more hours a week doing so and another $31 \%$ spending between 1-19 hours. 
2 In chi-squared tests the factors significantly associated with caring $20+$ hours a week were 3 predominantly financial. Respondents with a medical card were more likely to care for 20+ 4 hours than those without one (29\% vs. 17\%, p-value .023); those without private health 5 insurance caring were more likely to care for $20+$ hours than those with insurance (32\% vs. $617 \%$, p-value .0005); those finding it difficult to make ends were more likely to care for more 7 than $20+$ hours than those who found it easy to make ends meet (31\% vs. $16 \%$, p-value .0008); and those who were more concerned about their finances since their relative/friend's diagnosis were more likely to care for $20+$ hours than those without such concerns $(29 \%$ vs. $16 \%$, pvalue .001). Relationship status and stage of cancer in the care recipient were not associated with time spent caring.

\section{Head and neck cancer specific caring activities}

Table 3 describes the head and neck cancer specific tasks that carers assisted their relative/friend with in the past month. A substantial proportion of carers were helping with more general, non-medical tasks such as navigating the health system (53\%), helping their relative/friend manage their emotions (51\%) and looking after appointments (59\%). Fewer carers (though still almost 10\%) were helping with more cancer specific care activities such as feeding and breathing tubes. 76 carers (38\%) helped with five or more tasks in the past month, and another 76 (38\%) with 1-4 tasks; 45 (23\%) of carers did not help with any of these tasks in the past month.

For most tasks, most carers felt comfortable helping their relative friend, though carers appeared to be relatively more uncomfortable helping with the medical aspects of care such as feeding and breathing tubes and medical complications (Table 3). For example, $85 \%$ of respondents felt comfortable helping their relative/friend to navigate the healthcare system whereas only $50 \%$ felt comfortable assisting them with medical complications. In chi-squared tests, the main factors (significant at the $\mathrm{p}=0.05$ level) associated with feeling uncomfortable with head and neck specific cancer care tasks were: not having private health insurance, finding it difficult to make ends meet and feeling concerned about household finances .

\section{Psychological health}


1 Of the respondents who completed the depression subscale of the DASS-21 ( $\mathrm{n}=178), 66 \%$

2 scored in the normal range and 34\% reported experiencing any level of depression. 179

3 respondents completed the anxiety subscale; $75 \%$ scored in the normal range and $25 \%$ reported

4 experiencing any level of anxiety. 176 respondents completed the stress subscale and 80\%

5 scored in the normal range for stress, with $20 \%$ reporting experiencing any level of stress.

6

7 Depression

8 Table 4 shows the crude and adjusted odds ratios (ORs) for variables associated with depression of any severity. In the multivariable analysis the factors significantly associated with having any depression were: feeling uncomfortable helping with one or more head and neck cancer care tasks, being female, not having private health insurance and caring for a more recently diagnosed person. There was a borderline statistically significant association with time spent caring after adjusting for other factors $(\mathrm{p}=0.063)$.

\section{Anxiety}

In the multivariable analysis the factors significantly associated with having anxiety were: feeling uncomfortable helping with one or more head and neck cancer care tasks, finding it difficult to make financial ends meet since began caring for relative/friend, not being in paid work, having children and caring for someone with a more recent diagnosis. There was a borderline statistically significant association with time spent caring after adjusting for other factors $(\mathrm{p}=\mathbf{0 . 0 6 5})$.

\section{Stress}

In the multivariable analysis the factor significantly associated with having stress was finding it difficult to make financial ends meet in the past month. After adjusting for other factors, time spent caring $(\mathrm{p}=0.063)$ and feeling uncomfortable with one of more caregiving tasks $(\mathrm{p}=0.080)$ both showed a borderline statistically significant relationship with stress.

\section{Discussion}

This study investigated various aspects of the support activities that carers of survivors with head and neck cancer engage in and if these are related to psychological wellbeing. Overall, the results show that many carers in the post-treatment period appear to be relatively psychologically resilient, in the sense that the majority score in the normal range for anxiety, stress and depression. Many of them are not spending substantial amounts of time per month 
on cancer care activities and most are comfortable with the tasks they perform. However the results also indicate that a minority of carers are spending considerable amounts of time caring per week, are engaged in a significant number of care tasks, are uncomfortable with the tasks they are performing, or are experiencing negative psychological states.

Strengths and limitations

The strengths of the study include the relatively large sample of carers; and the fact that the study investigated issues (discomfort, time spent on caring tasks) that have received little attention from previous head and neck cancer researchers. There are several limitations to the study. Many of the questions about support (concerning caring tasks and time spent caring) focused solely on the 'past month'. While questions were asked in this way to maximise recall, it may be that some carers would have engaged in cancer support activities in the past, but not in the past month. Since the participants were nominated by care recipients as being involved in caring for them, it is likely that the results presented underestimate the activities that head and neck cancer carers engage in and the time spent on those activities across the survivorship continuum. The study's cross-sectional design means that we were unable to monitor changes in caregivers' activities over time, or changes in their psychological wellbeing. The head and neck specific task instrument that we devised was not a content validated instrument, though it does have face validity since its items were delineated by patients with head and neck cancer and head and neck cancer professionals.

\section{Caregiving tasks and psychological wellbeing}

Carers in this study engaged in a variety of head and neck cancer specific medical and nonmedical support activities (Table 3). The most common tasks that that carers engaged in were helping their relative/friend to manage their emotions, helping their relative/friend to navigate the healthcare system and looking after appointments. Head and neck cancer specific tasks that were medically focused, such as assisting with feeding and breathing tubes, were engaged in less often. This distribution of tasks mirrors that found in previous head and neck cancer studies, such as that of Precious et al. 2012. Most carers in the current study indicated that they felt comfortable engaging in most of the general support tasks, such as food preparation (Table 3). These findings contrast somewhat with other studies such as research by Patterson et al. (2013), which found that carers can sometimes be uncomfortable assisting with such activities. The difference between these findings might relate to the length of time that carers in this study 
had been helping their relative or friend (compared to Patterson et al., carers in this study had been caring for longer, and may have been more habituated to support tasks); alternatively, carers in Patterson's study may have been looking after patients with specific food-related difficulties (such as dysphagia) which carers in this study may not have had to deal with. However while most carers in the current study felt comfortable with general care tasks, it was notable that a relatively greater proportion of carers felt uncomfortable helping their relative/friend to manage their emotions compared with activities such as looking after appointments; as far as we are aware this is the first study to identify that head and neck cancer carers themselves can feel uncomfortable providing emotional support. This is an important finding given that providing emotional support is one of caregivers' key tasks, and one that is often overlooked by healthvcare professionals (Precious et al. 2012). Other studies of patients have noted that emotional management is one of the most stressful support activities that carers engage in (Precious et al. 2012), not least because carers may have to provide emotional support while simultaneously dealing with their own emotions in relation to the caregiving role (Penner et al. 2012).

It was also notable that while carers engaged in the medically specific care tasks (such as helping with feeding and breathing tubes and helping with medical complications) less frequently than the more general tasks (such as managing appointments), they generally felt more uncomfortable doing so (Table 3). It has been suggested that carers who are uncomfortable with a task may be unable to help the patient to the degree that is needed (Stenberg et al. 2010), suggesting that finding effective ways to increase carers' comfort is important for both the carer and the care recipient. Moreover, discomfort also predicted carer depression and anxiety, a finding that we have not seen previously reported in relation to carers of patients with head and neck cancer. Helping carers to resolve feelings of discomfort in relation to cancer support activities may therefore significantly improve psychosocial wellbeing among carers themselves and improve the support received by patients/survivors. What it is about a task that leads a carer to feel discomfort is unclear; for some tasks, it may be the length of time that people spend caring that leads to discomfort, while others (such as helping with breathing or feeding tubes), may be inherently uncomfortable to engage in. Further research could usefully seek to better explain this. Our findings also suggest a need for healthcare professionals to ascertain exactly why some carers feel uncomfortable with these tasks (for example, because they feel that they do not have enough knowledge, or the appropriate skills, or confidence in their abilities, to adequately implement them), and if 
necessary provide support, education or training to help carers overcome their feelings of discomfort.

\section{Time since diagnosis}

This study included carers of survivors at different points in the post-treatment trajectory. Some carers completed the survey more than ten years after the care recipient's diagnosis, others were less than five years. This is a common feature of research with carers for people with head and neck cancer, where samples are often heterogeneous (Longacre et al. 2012). We controlled for this heterogeneity by including time since diagnosis as an explanatory variable in our models. The evidence to date about the relationship between time since treatment and carers' mental wellbeing is mixed, with some finding that distress declines over time (Blood et al., 1994), and others that time since diagnoss is not associated with mental health (Ross et al. 2010). Our results support the argument that caregivers typically have better psychological health the further their care-recipient is out from treatment. This is likely because they are less involved in active caring than carers of more recently diagnosed patients. It may also be that long-term carers have reached an accomodation with the cancer and its impacts on their life, and are less likely to experience emotional disequilibrium as a result.

\section{Time spent on caregiving activities and psychological wellbeing} Just over a fifth of respondents spent 20 or more hours per week in the past month caring for their relative/friend (as assessed by the activities of daily living time use instrument); given that many of the participants were caring for longer-term survivors, these percentages are notable. Previous studies have found that extended caring can be a significant burden on carers and lead to reduced well-being (Ross et al. 2010; Olson et al. 2014). Extended caring can impact carers' lives in a variety of ways, for example reducing the time available to them for socializing, hobbies and travel (Nijboer et al. 1999; Longacre et al. 2012; Mosher et al. 2013; Girgis et al. 2013). Caring for 20+ hours per week is also likely to result in carers experiencing disruptions in their day-to-day schedules and lead them to end up juggling multiple- and often conflicting- tasks (Longacre et al. 2012; Mosher et al. 20130. Furthermore, carers may also experience significant stress as a result of wanting to help their relative/friend and feeling that their lives are restricted and disrupted by doing so (Mehta et al. 2014). They can be psychologically caught between wanting to help and feeling constrained. However it is also important to note that the statistical association found in this study between mental health 
and time spent caring was weak, and it appears another measure of care - discomfort with tasks was more strongly associated with poor psychological outcome.

\section{Financial difficulties}

Financial difficulties were prevalent in this sample, with just under half of carers finding it difficult to make ends meet in the past month and just under half indicating that their financial situation became more difficult since they began caring (Table 1). Although other studies have not specifically examined cancer-related financial stress and strain in head and neck caregivers, they do point to financial consequences of caregiving; for example, one study reported that, because cancer often prevents caregivers' from obtaining paid work, it sometimes results in carers (who are often partners or wives) using up the family savings (Jayani and Hurria, 2012). People with head and neck cancer and their carers also often come from disadvantaged economic backgrounds to start with (Rogers et al. 2011) and our study population is likely to be no different from others in this regard. Carers' financial problems could further stem from the fact that the majority of respondents were either retired or working at home, and may therefore have been living on a fixed and relatively marginal income. Caring, with its attendant costs such as travelling to hospital appointments, buying special foods etc., could also put substantial financial stress or strain on people who may not have significant resources at the outset. Our findings also indicated (for the first time, as far as we are aware) that financial difficulties were significant predictors of stress and anxiety in head and neck cancer caregivers. Greater financial resources may play a buffering psychological role for people who are caring for survivors of head and neck cancer, with those with more resources having more options to escape from the caring burden, for example by securing formal care services that can provide psychological relief. Those with fewer resources however may be trapped firmly in the caring role with few possibilities to escape from its demands (Gaugler et al. 2005).

\section{Implications for services}

A significant predictor of carers' psychological distress in this study was discomfort with cancer care tasks. For (at least some) carers this discomfort may stem from lack of knowledge, confidence and skill about cancer care activities, such as how to assist with breathing and feeding tubes. It has been previously noted that many cancer carers receive no formal training, and that many of them feel unprepared for their caring responsibilities or have too much responsibility placed on them (Bookman et al. 2007). Healthcare professionals (psychooncology and general medical) might be able to supply some carers with the support 
and training that they need to address their discomfort; though this requires health professionals to be ready to ascertain and assess carers' levels of comfort. With this knowledge at least some carers should feel more empowered and have greater feelings of mastery and control, which could in turn serve to combat feelings of helplessness, anxiety and stress. Where resources are available the findings also suggest that it might be useful for healthcare professionals (especially community based health professionals) to assist with care tasks that caregivers find especially uncomfortable. Secondly, the findings indicate that health professionals need to pay particular attention to carers of people with head and neck cancer who are at risk of poor mental health, such as those with financial issues, those who are older and those caring for substantial amounts of time per week. Thirdly, there is a need for researchers to develop a fully validated instrument (rather than just face validated) to assess time and task burden in head and neck cancer caregivers.

\section{Conclusion}

The results of this study suggest that, in the post-treatment period, many informal carers of head and neck cancer patients appear to be doing reasonably well. However the results also indicate that there is a minority of carers who are spending large amounts of time caring per week, who are engaged in a significant number of care tasks, who are uncomfortable with the tasks they are performing, and who are experiencing negative psychological states. Efforts to identify and address the reasons why carers are discomforted by caring could be a quick and cost-effective way to mitigate psychological issues in this group. 
7 Acknowledgements

8 Funding for the study was provided by the Irish Health Research Board. The funding body did 9 not have a role in the study design or in any other phase of the project (collection, analysis or 10 interpretation of data). The funding body had no say in the authors decision to submit the 11 manuscript. 


\section{References}

8 Badr, H., Gupta, V, Sikora, A., Posner, M. (2014). Psychological distress in patients and caregivers over the course of radiotherapy for head and neck cancer. Oral Oncology, 50, 10051011.

Blood, G., Simpson, K., Dineen, M., Kauffman, S., Raimondi, S. (1994). Spouses of indivdiuals with laryngeal cancer: caregiver strain and burden. Journal of Communication Disorders 27, 19-35.

Bookman, A., Harrington, M (2007) Family caregivers: a shadowy workforce in the Geriatric health care system. Journal of Health Politics Policy Law 32, 1005-1041.

Dempster, M., McCorry, N., Brennan, E., Donnelly, M., Murray, L., Johnston, B (2011) Illness perceptions among carer-survivor dyads related to psychological distress among Oesophageal cancer survivors. Journal of Psychosomatic Research, 70, 432-439.

Drabe, N., Zwahlen, D., Buchi, S., Moergeli, H., Zwahlen, R., Jenewein, J. (2008) Psychiatric morbidity and quality of life in wives of men with long-term head and neck cancer. Psychooncology 17, 199-204.

Francouer, R (2005) Cumulative financial stress and strain in palliative radiation outpatients: the role of age and disability. Acta Oncology 44, 369-381.

Gaugler, J., Hanna, N., Linder, J., Given, C., Tolbert, V., Kataria, R., Regine, W (2005) Cancer 
1 Girgis, A and Lambert S (2009). Caregivers of cancer survivors: the state of the field. Cancer

2 Forum, 3, 3.

3

4 Girgis, A., Lambert, S., Johnson, C., Waller, A., Currow, D (2013) Physical, psychosocial, 5 relationship and economic burden of caring for people with cancer: a review. Journal of 6 Oncology Practice, 9, 197-202.

7

8 Given, B., Given, C., Kozachik, S. (2001). Family support in advanced cancer. Canadian 9 Journal of Clinical Cancer, 51, 213-231.

10

Hanly, P., O, Ceilleachair. A, Skally, M., O’ Leary, E., Kapur, K., Fitzpatrick, P., Stains, A. and Sharp, L. (2013) How much does it cost to care for survivors of colorectal cancer? Caregivers's time, travel and out-of-pocket costs. Supportive Care and Cancer 21, 2585-2592.

Henry, J., Crawford, J. (2005) The short-form version of the Depression Anxiety Stress Scales (DASS-21): Construct validity and normative data in a large non-clinical sample. British Journal of Clinical Psychology 44, 227-239.

Hodges, L., Humphris, G. (2009). Fear of recurrence and psychological distress in head and neck cancer patients and their carers. Psychooncology 18, 841-848.

Hosmer, D., Hosmer, T., Le Cessie, S., Lemeshow, S (1997) A comparison of goodness-of-fit tests for the logistic regression model. Statistical Medicine 16, 965-980.

Jayani, R., Hurria, A. (2012) Caregivers of older adults with cancer. Seminars in Oncology Nursing 28, 221-225.

Krouse, R. (2014) Caregivers as healthcare managers: health management activities, needs, and caregiving relationships for colorectal cancer survivors with ostomies. Support Care and Cancer 22, 2401-2408.

Lambert S., Girgis, A., Lecthelinais, C., Stacey, F (2013) Walking a mile in their shoes: anxiety and depression among partners and caregivers of cancer survivors at 6 and 12 months postdiagnosis. Support Care Cancer 21, 75-85. 
2 Lee., Y., Lin, P., Chieln, C., Fang, F. (2014) Prevalence and risk factors of depressive disorder 3 in caregivers of patients with head and neck cancer. Psycho-oncology doi: 10.1002/pon.3619.

4 6 7

Longacre, M., Ridge, J., Burtness, B., Galloways, T., Fang, C. (2012) Psychological functioning of caregivers for head and neck cancer patients. Oral Oncology, 48, 18-25.

Lovibond, S. and Lovibond, P. (1995). Manual for the Depression. Anxiety, Stress Scales.

Maddensm J, Utley, M., Moller, H. (2012). Projections of cancer prevalence in the United Kingdom, 2010-2040. British Journal of Cancer, 107, 1195-1202.

McMullen, C., Schneider, J., Altschuler, A., Grant, M., Hornbrook, N., Liliestrand, P., Krouse, R. (2014). Caregivers as healthcare managers: health management activities, needs, and caregiving relationships for colorectal cancer survivors with ostomies. Supportive Care and Cancer 22, 2401-2408.

Mehanna, H., Paleri, V., West, C., Nutting, C. (2010) Head and Neck Cancer: Epidemiology, Presentation and prevention. British Medical Journal 341, 663-666.

Mehta, A., Chan, L., Cohen, S (2014) Flying blind: sources of distress for family caregivers of palliative cancer patients managing cancer at home. Journal of Psychosocial Oncology 32, 94111.

Moshe, C., Jaynes, H,, Hanna, N. and Ostroff J (2013). Distressed family caregivers of lung cancer patients: an examination of psychosocial and practical challenges. Supportive Care and Cancer 21, 431-437.

Nijboer, C., Templaar, R., Sanderman, R., Triemstra, M., Spruit, R., Bos, G. (1998) Cancer and caregiving: the impact on the caregiver's health. Psychooncology 7, 3-13

Nijboer, C., Tempelaar, R., Sanderman, R., Triemstra, M., Spruit, R., Bos, G (1999). Determinants of caregiving experiences and mental health of partners of cancer patients. Cancer 86, 577-588. 
2 Olson, R. (2014). A time-sovereignty approach to understanding carers of cancer patients' experiences and support preferences. European Journal of Cancer Care 23, 239-248.

Otis-Green, S., Juarez, G (2012) Enhancing the social well-being of family caregivers. 6 Seminars in Oncology Nursing 28, 246-255.

7

8 Oyebode, J (2003) Assessment of carers' psychological needs. Advances in Psychiatric 9

10

Treatment 9, 45-53.

Patterson, J., Rapley, T., Carding, P., Wilson, J., McColl, E. (2013) Head and neck cancer and dysphagia: caring for carers. Psychooncology 22, 1815-1820.

Pearce, A., Timmons, A., O’ Sullivan, E., Gallagher, P., Gooberman-Hill, R., Thomas, A., Molcho, M., Butow, P., Sharp, L (2014). Long-term workforce participation patterns following head and neck cancer. Journal of Cancer Survivorship. 2014, PMID:25060809

Penner, J., McClement, S., Lobchuk, M., Daeninck, P. (2012) Family members' experiences caring for patients with advanced head and neck cancer receiving tube feeding: a descriptive phenomenological study. Journal of Pain and Symptom Management 44, 563-571.

Precious, E., Haran, S., Lowe, D., Rogers, S. (2012) Head and neck cancer patients' perspectives of carer burden. British Journal of Oral and Maxillofacial Surgery 50, 202-207.

Romito, F., Goldzweig, G., Cormio, C., Hagedoom, M., Andersen, B (2013) Informal caregiving for cancer patients. Cancer 21, 2160-2169.

Rogers, S., Clifford, N., Lowe, D (2011) Patient and carer unmet needs: a survey of the British association of head and neck oncology nurses. British Journal of Oral and Maxillofacial Surgery 49, 343-348.

Ross, S., Mocher, C., Ronis-Tobin, V., Hermele, S., Ostroff, J. (2010). Psychosocial adjustment of family caregivers of head and neck cancer survivors. Supportive Care and Cancer 18, 171-178. 
2 Sharp, L., Carsin, A., Timmons, A (2013) Associations between cancer-related financial stress and strain and psychological well-being among individuals living with cancer. Psychooncology 22, 745-755.

5 Stenberg, U., Ruland, C., Miaskowski, C. (2010). Review of the literature on the effects of 6 caring for a patient with cancer. Psychooncology 19, 1013-1025.

7

8 Thomas, A., Timmons, A., Molcho, M., Pearce, A., Gallagher, P., Butow, P., O’ Sullivan, E., 9 Gooberman-Hill, R., O’ Neill, C. and Sharp, L (2014). Quality of life in urban and rural settings: a study of head and neck cancer survivors. Oral Oncology, 50, 676-682.

Verdonck-de Leeuw, I., Eerenstein, S., Linden, M., Kuik, D., de Bree, R (2007) Distress in spouses and patients after treatment for head and neck cancer. The Laryngoscope 117, 238241.

Vickery, L., Latchford, G., Hewison, J., Bellew, M., Feber., T (2003) The impact of head and neck cancer and facial disfigurement on the quality of life of patients and their partners. Head and Neck 25, 289-296.

Yabroff, K. amd Youong, K (2009). Time costs associated with informal caregiving for cancer survivors. Cancer 115, 4362-4367. 
7 Tables

8 Tables

9

10 Table 1. Characteristics of carers of survivors of head and neck cancer.

\begin{tabular}{lrr}
\hline & $\mathbf{n}$ & $(\boldsymbol{\%})$ \\
\hline number of respondents & 197 & $(100)$ \\
Socio-demographic & & \\
sex & & \\
Male & 44 & $(22)$ \\
Female & 150 & $(76)$ \\
Not reported & 3 & $(2)$ \\
current marital status & & \\
married/partner & 171 & $(88)$ \\
not married & 24 & $(12)$ \\
Not reported & 2 & $(1)$ \\
have children & & \\
Yes & 168 & $(85)$ \\
No & 24 & $(12)$ \\
not reported & 5 & $(3)$ \\
employment status & & \\
paid employment & 64 & $(32)$ \\
looking after family/home & 52 & $(26)$ \\
retired/unemployed/disability & 80 & $(41)$
\end{tabular}

Financial

ability to make financial

ends meet in last month 


\begin{tabular}{|c|c|c|}
\hline difficult & 100 & $(51)$ \\
\hline easy & 96 & (49) \\
\hline Not reported & 1 & $(<1)$ \\
\hline \multicolumn{3}{|c|}{ effect of caring on ability to } \\
\hline \multicolumn{3}{|l|}{ make ends meet } \\
\hline more difficult & 94 & $(48)$ \\
\hline no change & 88 & $(45)$ \\
\hline less difficult & 10 & (5) \\
\hline Not reported & 5 & (2) \\
\hline \multicolumn{3}{|c|}{ feelings about household } \\
\hline \multicolumn{3}{|c|}{ finances since diagnosis } \\
\hline more concerned & 114 & $(58)$ \\
\hline no change & 68 & (34) \\
\hline less concerned & 12 & (6) \\
\hline Not reported & 3 & (2) \\
\hline \multicolumn{3}{|c|}{ medical card (entitling } \\
\hline \multicolumn{3}{|c|}{ bearer to free medical care) } \\
\hline Yes & 106 & $(54)$ \\
\hline No & 87 & (44) \\
\hline Not reported & 4 & (2) \\
\hline \multicolumn{3}{|c|}{ private medical insurance } \\
\hline Yes & 102 & $(52)$ \\
\hline No & 84 & (43) \\
\hline Not reported & 11 & (5) \\
\hline \multicolumn{3}{|c|}{ Time since cancer diagnosis } \\
\hline \multicolumn{3}{|l|}{ of care recipient } \\
\hline$<5$ years & 91 & $(46)$ \\
\hline $5-9.99$ years & 70 & $(35)$ \\
\hline $10+$ years & 29 & $(15)$ \\
\hline Not reported & 7 & (4) \\
\hline
\end{tabular}

1 
$6 \quad$ Table 2: Time per week spent on household activities and cancer related assistance activities 7 as a result of caring in the last month

\begin{tabular}{|c|c|c|c|c|c|c|c|c|}
\hline \multirow[t]{2}{*}{ Activity } & \multicolumn{2}{|c|}{0 hours } & \multicolumn{2}{|c|}{ 1-5 hours } & \multicolumn{2}{|c|}{ 6+ hours } & \multicolumn{2}{|c|}{ Any time } \\
\hline & $\mathbf{n}$ & $(\%)$ & & $(\%)$ & $\mathbf{n}$ & $(\%)$ & $\mathbf{n}$ & $\%$ \\
\hline Cleaning house & 134 & $(68)$ & 34 & (17) & 29 & (15) & 63 & (32) \\
\hline Washing ironing & 151 & (77) & 33 & (17) & 13 & (7) & 46 & (24) \\
\hline Shopping & 128 & $(65)$ & 51 & $(26)$ & 18 & (9) & 69 & $(35)$ \\
\hline Odd jobs & 140 & $(71)$ & 39 & $(20)$ & 18 & (9) & 57 & (29) \\
\hline Preparing food & 132 & $(67)$ & 38 & (19) & 27 & (14) & 65 & (33) \\
\hline $\begin{array}{l}\text { Assisting } \\
\text { relative/friend with } \\
\text { personal care }\end{array}$ & 176 & $(89)$ & 12 & (6) & 9 & (5) & 21 & (11) \\
\hline Cancer specific care & 167 & $(85)$ & 17 & (9) & 13 & (7) & 30 & (16) \\
\hline $\begin{array}{l}\text { Assisting } \\
\text { relative/friend move } \\
\text { around house }\end{array}$ & 188 & (95) & 8 & (4) & 1 & (1) & 9 & (5) \\
\hline $\begin{array}{l}\text { Helping } \\
\text { relative/friend with } \\
\text { eating and drinking }\end{array}$ & 184 & (93) & 9 & (5) & 4 & (2) & 13 & (7) \\
\hline Making trips & 149 & (76) & 31 & (16) & 17 & (9) & 48 & (25) \\
\hline Visiting doctor & 122 & $(62)$ & 56 & (28) & 19 & $(10)$ & 75 & (38) \\
\hline $\begin{array}{l}\text { Assisting with } \\
\text { financial matters }\end{array}$ & 152 & (77) & 34 & (17) & 11 & (6) & 45 & (23) \\
\hline
\end{tabular}

8 
6 Table 3 : Head and neck cancer specific activities that carers assisted survivors with in the 7 past month, and carers' level of comfort with helping with these activities

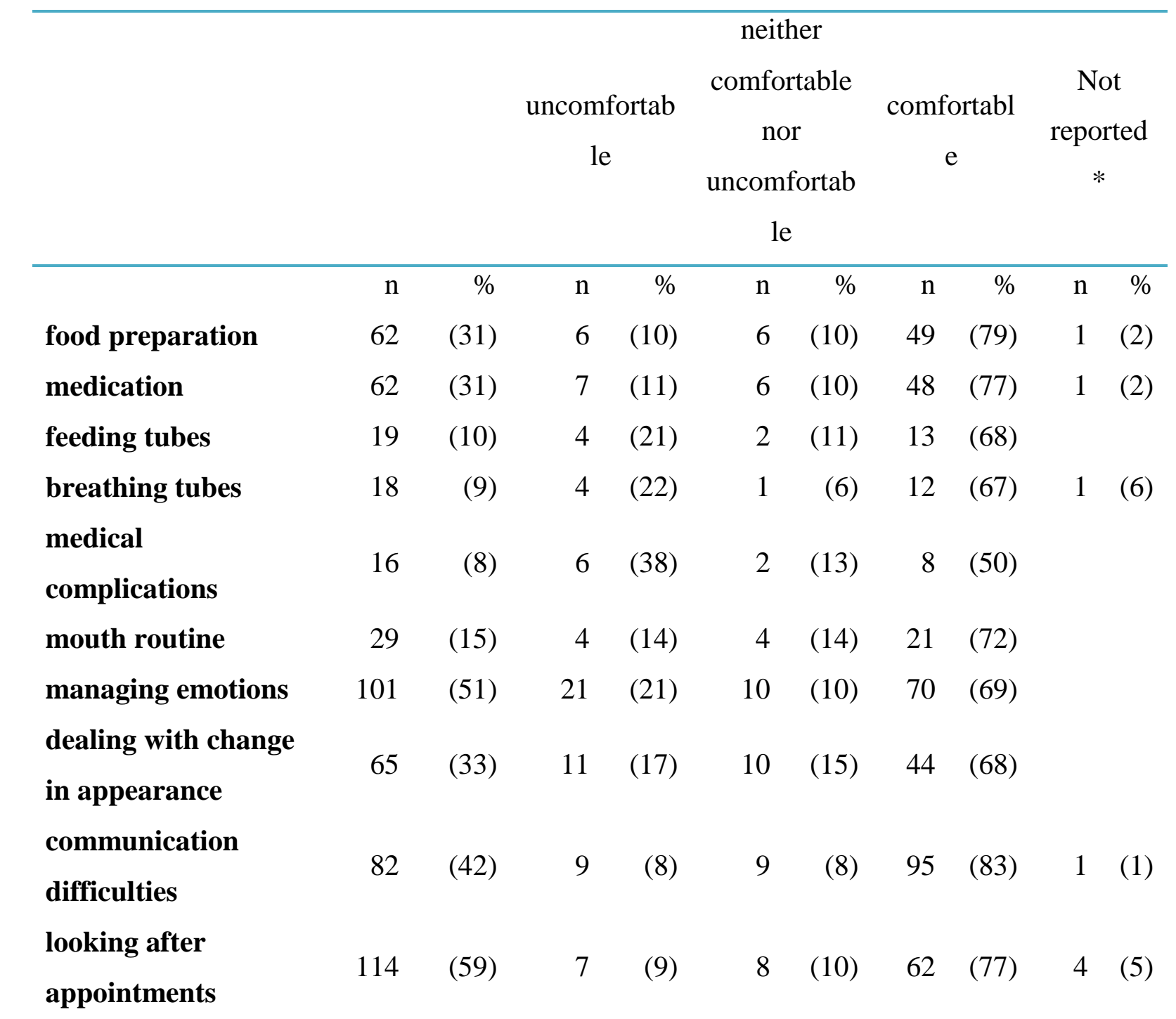




\section{financial}

management

navigate healthcare

system $\begin{array}{lllllll}81 & (41) \quad 21 & (26) & 6 & (7) & 55 & (67)\end{array}$

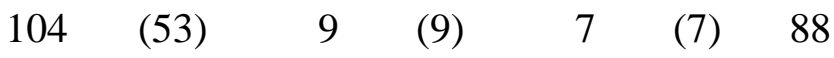

$1 *$ Missing values refer to respondents who indicated that they helped with an activity, but did

2 not indicate whether or not they felt comfortable doing so.

3 Table 4. Variables associated with depression, anxiety and stress; multiple logistic

4 regression (OR) with $95 \%$ confidence intervals and p-values.

5

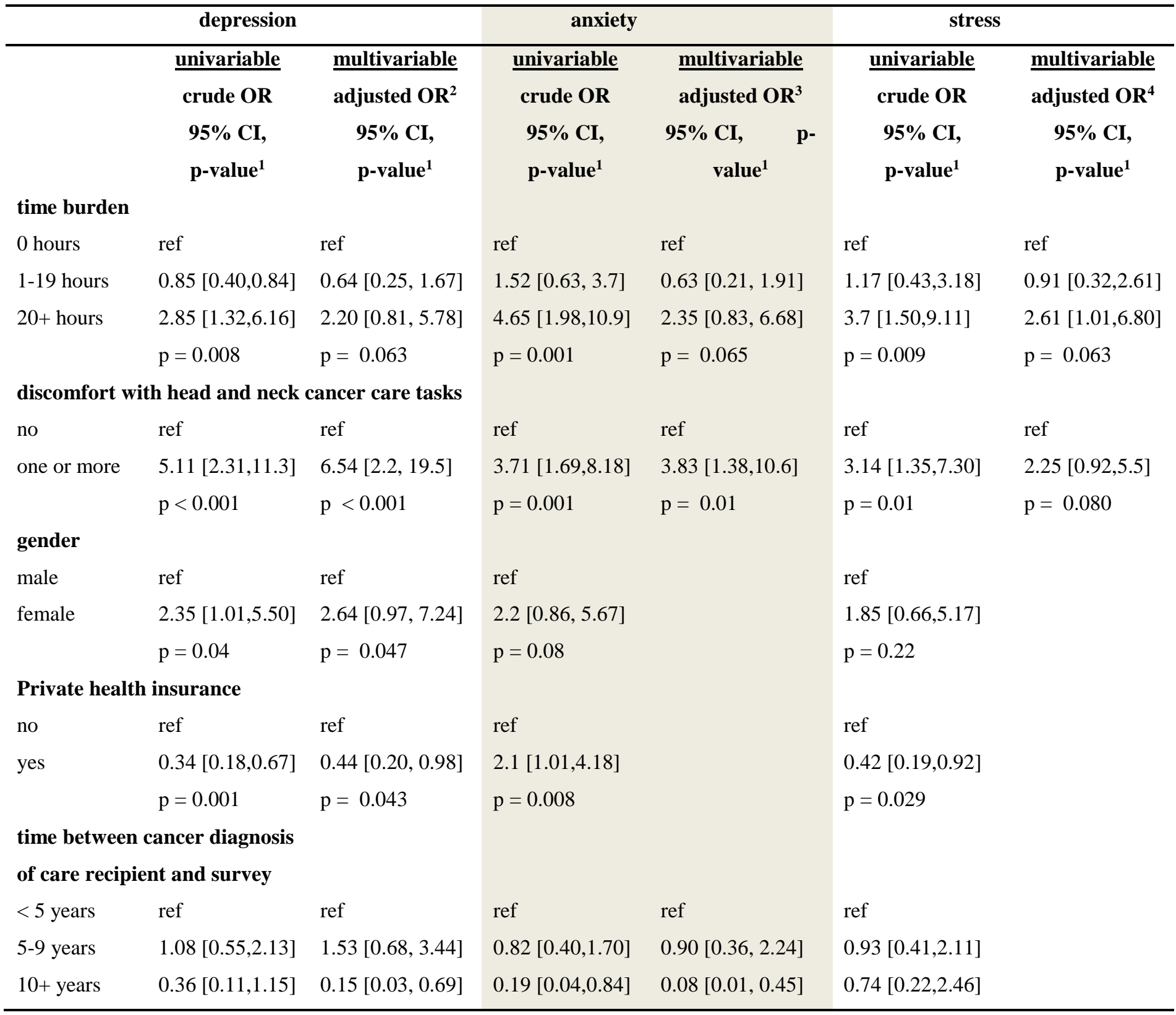




$\begin{array}{lllll}\mathrm{p}=0.101 & \mathrm{p}=0.037 & \mathrm{p}=0.03 & \mathrm{p}=0.002 & 0.88\end{array}$

\section{Carer age at}

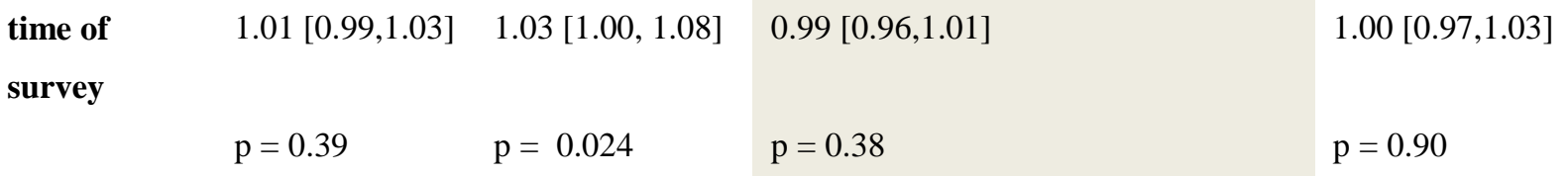

\section{Ability to make financial ends}

meet in the past month

$\begin{array}{ll}\text { easy } & \text { ref } \\ \text { difficult } & 2.40[1.26,4.58] \\ & \mathrm{p}=0.007\end{array}$

\section{Effect of caring on ability to}

\section{make ends meet}

same/less

ref

re

$3.93[1.83,8.43] \quad 4.5[1.7,11.8]$

$\mathrm{p}=0.0002$

$\mathrm{p}=0.001$

$3.34[1.46,7.67]$

$\mathrm{p}=0.003$

ref

$2.6[1.09,6.24]$

$\mathrm{p}=0.026$

ref

ref

$3.06[1.48,6.30]$

$2.88[1.30,6.38]$

$\mathrm{p}=0.002$

$\mathrm{p}=0.007$

Feel about household finances since

\section{relative/friend's diagnosis}

same/less

concerned

ref

ref

ref

more

concerned

$$
2.05[1.06,3.94]
$$

$3.77[1.68,8.46]$

$2.44[1.06,5.60]$

$$
\mathrm{p}=0.03
$$

$\mathrm{p}=0.0005$

$\mathrm{p}=0.03$

\begin{tabular}{|c|c|}
\hline not employed & ref \\
\hline paid employ & $0.48[0.23,1.02]$ \\
\hline $\begin{array}{l}\text { looking after } \\
\text { family/home }\end{array}$ & $0.92[0.43,1.96]$ \\
\hline & $\mathrm{p}=0.12$ \\
\hline medical card & \\
\hline no & ref \\
\hline yes & $1.69[0.89,3.20]$ \\
\hline & $\mathrm{p}=0.11$ \\
\hline have children & \\
\hline no & ref \\
\hline yes & $2.8[0.91,8.66]$ \\
\hline & $\mathrm{p}=0.05$ \\
\hline
\end{tabular}

\section{Employment status}

$\begin{array}{lll}\text { ref } & \text { ref } & \text { ref } \\ 0.35[0.14,0.88] & 0.20[0.07,0.61] & 0.51[0.20,1.32] \\ 1.11[0.50,2.44] & 0.55[0.19,1.57] & 0.94[0.39,2.27] \\ \mathrm{p}=0.03 & \mathrm{p}=0.01 & \mathrm{p}=0.32 \\ & & \\ \text { ref } & & \text { ref } \\ 2.10[1.01,4.18] & & 2.33[1.03,5.26] \\ \mathrm{p}=0.04 & & \mathrm{p}=0.035 \\ \mathrm{ref} & & \mathrm{ref} \\ 8.78[1.15,67.1] & 10.8[1.23,95] & 1.71[0.48,6.11] \\ \mathrm{p}=0.004 & \mathrm{p}=0.006 & \mathrm{p}=0.39\end{array}$


$1 \quad{ }^{1} \mathrm{p}$-value from likelihood ratio test.

$2{ }^{2}$ multivariable logistic regression model adjusted for time burden, uncomfortable doing one

3 or more tasks, gender, health insurance, time since diagnosis and age.

$4{ }^{3}$ multivariable logistic regression model adjusted for time burden, uncomfortable doing one

5 or more tasks, time since diagnosis, ability to make ends meet, employment status and have

6 children.

$7{ }^{4}$ multivariable logistic regression model adjusted for time burden, uncomfortable doing one

8 or more tasks and ability to make ends meet.

9

10 Table S1: demographic and clinical variables of care-recipient population

\begin{tabular}{|c|c|c|}
\hline $\begin{array}{l}\text { Cancer survivor } \\
\text { characteristics }\end{array}$ & No. & $\%$ \\
\hline \multicolumn{3}{|l|}{ age } \\
\hline$<50$ years & 43 & 21.8 \\
\hline $60-64$ years & 102 & 51.8 \\
\hline $65+$ years & 51 & 25.9 \\
\hline unknown & 1 & 0.5 \\
\hline \multicolumn{3}{|l|}{$\operatorname{sex}$} \\
\hline female & 62 & 31.6 \\
\hline male & 134 & 68.4 \\
\hline unknown & 1 & 0.5 \\
\hline \multicolumn{3}{|l|}{ marital status } \\
\hline married/living with partner & 158 & 80.2 \\
\hline not living with partner & 38 & 19.3 \\
\hline unknown & 1 & 0.5 \\
\hline \multicolumn{3}{|l|}{$\begin{array}{l}\text { head and neck cancer } \\
\text { return/spread }\end{array}$} \\
\hline no & 178 & 90.4 \\
\hline yes & 10 & 5.1 \\
\hline unknown & 9 & 4.6 \\
\hline \multicolumn{3}{|l|}{ medical card } \\
\hline no & 101 & 51.3 \\
\hline yes & 92 & 46.7 \\
\hline unknown & 4 & 2 \\
\hline \multicolumn{3}{|l|}{ private health insurance } \\
\hline no & 102 & 51.8 \\
\hline yes & 87 & 44.2 \\
\hline unknown & 8 & 4.1 \\
\hline \multicolumn{3}{|l|}{ have children } \\
\hline no & 33 & 16.8 \\
\hline yes & 158 & 80.2 \\
\hline unknown & 6 & 3 \\
\hline \multicolumn{3}{|l|}{ live alone } \\
\hline no & 169 & 85.8 \\
\hline yes & 24 & 12.2 \\
\hline unknown & 4 & 2 \\
\hline \multicolumn{3}{|l|}{ education } \\
\hline primary school & 61 & 31 \\
\hline
\end{tabular}




$\begin{array}{lrr}\text { secondary school } & 86 & 43.7 \\ \text { 3rd/4th level } & 43 & 21.8 \\ \text { unknown } & 7 & 3.6 \\ \text { residence } & & \\ \text { Dublin } & 49 & 24.9 \\ \text { other city/town/village } & 89 & 45.2 \\ \text { countryside } & 58 & 29.4 \\ \text { unknown } & 1 & 0.5 \\ \text { employment } & & \\ \text { paid employment } & 86 & 43.7 \\ \text { not paid employment } & 110 & 55.8 \\ \text { unknown } & 1 & 0.5 \\ \text { stage } & & \\ 1 & 60 & 30.5 \\ 2 & 28 & 14.2 \\ 3 & 21 & 10.7 \\ 4 & 54 & 27.4 \\ \text { unknown } & 34 & 17.3 \\ \text { chemotherapy }{ }^{*} & & \\ \text { yes } & 147 & 74.6 \\ \text { no } & 49 & 24.9 \\ \text { unknown } & 1 & 0.5 \\ \text { radiotherapy* } & & \\ \text { yes } & 63 & 32 \\ \text { no } & 133 & 67.5 \\ \text { unknown } & 1 & 0.5 \\ \text { other treatment }^{*} & 162 & 82.2 \\ \text { yes } & 34 & 17.3 \\ \text { no } & 1 & 0.5 \\ \text { unknown } & & \\ \text { surgery* } & & 29.9 \\ \text { yes } & 137 & 69.5 \\ \text { no } & 1 & 0.5 \\ \text { unknown } & & \end{array}$

1

$2 \quad$ treatment receipt within 8 months of diagnosis

3

4

5

6

7

8

9

10

11

12

13

14 


$$
1
$$

2

3

4

5

6

7

8

9

10

11

12

13

14

15

16

17

18

19

20

21

22

23

24

25

26

27

28

29

30 